\title{
Which is the best surgical approach for anorectal gastrointestinal stromal tumors in the post-imatinib era?
}

\author{
S. Pucciarelli $\cdot$ I. Maretto
}

Received: 25 March 2013/Accepted: 11 April 2013/Published online: 27 April 2013

(C) Springer-Verlag Italia 2013

\begin{abstract}
Anorectal gastrointestinal stromal tumors (GISTs) represent about $5 \%$ of all GISTs. Local recurrence, although with a long latency period, occurs in more than a half of cases and is a major concern. Prognostic factors for recurrence are the tumor size and the mitotic index. However, for anorectal lesions, the particular location represents a main obstacle to achieving a radical (R0) resection.
\end{abstract}

Surgery is the treatment of choice for patients with localized or potentially resectable GIST lesions. The goal is to achieve complete gross resection of the tumor with an intact pseudocapsule. Current guidelines recommend wide resection with clear margins (such as abdominoperineal or anterior resection) [1, 2]. Local removal of the tumor has also been proposed, performed by a transanal, transsacral, or transvaginal approach, even if abdominal surgery is more likely to result in negative margins than local surgery [3]. In the article by Centonze et al. [4], a new local technique has been proposed for anorectal GIST excision. A transsphincteric approach was used, with a right ischiorectal fossa incision. Although in the two cases presented the tumor size was $\geq 8 \mathrm{~cm}$ and the mitotic index was high, the procedure seems feasible, with low morbidity and good early oncological outcomes. Both the patients underwent adjuvant therapy with imatinib, as recommended for high risk GISTs.

There are two important considerations to be made. The first concerns the preoperative workup. All anorectal GIST patients should be managed by a multidisciplinary team

S. Pucciarelli $(\varangle) \cdot$ I. Maretto

Clinica Chirurgica I, Department of Surgery, Oncology, and

Gastroenterology, University of Padua, Via Giustiniani, 2,

35128 Padua, Italy

e-mail: puc@unipd.it with expertise in sarcoma. The workup should include: history, physical examination, abdominal/pelvic computed tomography (CT) scan with contrast and/or magnetic resonance imaging (MRI), and chest imaging. A positron emission tomography (PET) scan is not a substitute for CT, however, it may be used to clarify ambiguous findings seen on CT or MRI. Finally, endoscopic ultrasound-guided fine needle aspiration biopsy is necessary to confirm the diagnosis of primary GIST prior to the initiation of any preoperative therapy [5].

The second concerns the use of imatinib associated with surgery. This selective inhibitor of the KIT protein tyrosine kinase has drastically improved the prognosis of patients with GIST. The results of a recently completed trial suggest that in patients with a high risk of recurrence adjuvant imatinib administered for 36 months significantly improves relapse-free and overall survival compared to 12 months of imatinib therapy [6]. Since sphincter-sparing surgery is a primary goal in treating rectal tumors, the use of preoperative imatinib has also been investigated. The published trials show that preoperative imatinib is safe, and associated with a higher R0 rate, lower risk of tumor rupture, acceptable perioperative morbidity, and good disease-free survival [7-10]. However, the survival benefit is not well determinable since most of the patients included in these studies also received imatinib postoperatively for at least 2 years [7-9]. Thus, at the present time, the decision to use preoperative therapy for patients with resectable primary, locally advanced, or recurrent GIST should be made on an individual basis.

In our opinion, patients with high risk anorectal GIST (tumor size $>5 \mathrm{~cm}$ and/or documented mitotic rate $>5$ mitoses/50 high power field) should be treated with preoperative imatinib, followed by sphincter-saving surgery. Adjuvant imatinib for high-risk patients should be 
mandatory for a period of at least 3 years. Finding the best sphincter-saving strategy and the best approach to perform a local excision of GISTs is still a challenge. Several factors must be taken into account: tumor localization, with anatomical relationships, size and mitotic index of the mass, responsiveness to imatinib, and the patient's wishes. In spite of the encouraging results reported by Centonze et al. and by other authors [4, 11-14], further and larger studies are required to assess whether local resection, with or without e neoadjuvant imatinib therapy, is a safe and effective approach. However, in the post-imatinib era, current guidelines about resection margins and the transabdominal approach for anorectal GIST should be revised, because, in selected patients, wide resection margins and an abdominoperineal excision may be overtreatment.

Conflict of interest None.

\section{References}

1. Casali PG, Blay JY (2010) Gastrointestinal stromal tumours: ESMO clinical practice guidelines for diagnosis, treatment and follow-up. Ann Oncol 21(Suppl 5):v98-v102

2. Demetri GD, von Mehren M, Antonescu CR et al (2010) NCCN task force report: update on the management of patients with gastrointestinal stromal tumors. J Natl Compr Canc Netw 8(Suppl 2):S1-S41 quiz S42-S44

3. Jakob J, Mussi C, Ronellenfitsch U et al (2013) Gastrointestinal stromal tumor of the rectum: results of surgical and multimodality therapy in the era of imatinib. Ann Surg Oncol 20:586-592

4. Centonze D, Pulvirenti E, Pulvirenti D’Urso A, Franco S, Cinardi N, Giannone G (2013) Local excision with adjuvant imatinib therapy for anorectal gastrointestinal stromal tumors. Tech Coloproctol. doi:10.1007/s10151-013-0976-0

5. Sepe PS, Moparty B, Pitman MB, Saltzman JR, Brugge WR (2009) EUS-guided FNA for the diagnosis of GI stromal cell tumors: sensitivity and cytologic yield. Gastrointest Endosc 70:254-261

6. Joensuu H, Eriksson M, Sundby Hall K et al (2012) One versus three years of adjuvant imatinib for operable gastrointestinal stromal tumor: a randomized trial. JAMA 307:1265-1272

7. Eisenberg BL, Harris J, Blanke CD et al (2009) Phase II trial of neoadjuvant/adjuvant imatinib mesylate (IM) for advanced primary and metastatic/recurrent operable gastrointestinal stromal tumor (GIST): early results of RTOG 0132/ACRIN 6665. J Surg Oncol 99:42-47

8. McAuliffe JC, Hunt KK, Lazar AJ et al (2009) A randomized, phase II study of preoperative plus postoperative imatinib in GIST: evidence of rapid radiographic response and temporal induction of tumor cell apoptosis. Ann Surg Oncol 16:910-919

9. Blesius A, Cassier PA, Bertucci F et al (2011) Neoadjuvant imatinib in patients with locally advanced non metastatic GIST in the prospective BFR14 trial. BMC Cancer 11:72

10. Fiore M, Palassini E, Fumagalli E et al (2009) Preoperative imatinib mesylate for unresectable or locally advanced primary gastrointestinal stromal tumors (GIST). Eur J Surg Oncol 35:739745

11. Agaimy A, Vassos N, Märkl B et al (2013) Anorectal gastrointestinal stromal tumors: a retrospective multicenter analysis of 15 cases emphasizing their high local recurrence rate and the need for standardized therapeutic approach. Int J Colorectal Dis. doi: 10.1007/s00384-013-1655-3

12. Arezzo A, Verra M, Morino M (2011) Transanal endoscopic microsurgery after neoadjuvant therapy for rectal GIST. Dig Liver Dis 43:923-924

13. Matsushima K, Kayo M (2007) Transsacral approach to respect a gastrointestinal stromal tumor in the rectum: report of two cases. Surg Today 37:698-701

14. Hellan M, Maker VK (2006) Transvaginal excision of a large rectal stromal tumor: an alternative. Am J Surg 191:121-123 